\title{
Polydipsia in the pigeon
}

IIIKI I, SH, I.AB. Iresn Suate College, fresno. Citit 4.3726 and JAMLS 1. . IVITLRSOS, liniersity of California. Santa Barbara, Calif. 93106

Overdrinking was denonstrated in a single pigeon when session water intake under a number of relatively long intermittent schedules of reinforcement was compared with levels of drinking in several control conditions. Overdrinking was found to be specifically related to certain reinforcement conditions (2-min fixed and variable-interval schedules) as well as to the location of the water source in the experimental chamber. Moreover, drinking increased considerably following 3 days of interpolated extinction.

A number of recent studies (Falk, 1964, 1967) have reported that rats drink in excess of the normal intake when given food on an intermittent schedule. Most studies have attempted to account for the polydipsia by invoking either thirst or adventitious reinforcement (Clark, 1962; Stein, 1964). All these studies have used laboratory rats as Ss. The present research attempts to extend the generality of previous findings to pigeons and to investigate the specific effects of certain schedule changes on the development of polydipsia.

\section{SUBJECTS}

One male experienced White Carneau pigeon about 8 years old was maintained at $80 \%$ of its free-feeding weight throughout the study.

\section{APPARATUS}

A standard Lehigh Valley experimental chamber for pigeons was used. Water was continuously available to the bird during each experimental session in a 500-g removable translucent polyethelene beaker which could be rigidly fixed at any point along all four walls of the chamber by means of a movable aluminum holder. This beaker was always filled to the $300-\mathrm{g}$ level. Total session evaporation in the closed chamber, with an exhaust fan continuously operating, was never observed to exceed $1 \mathrm{~g}$. Total session water and food intake was measured to the nearest gram follow. ing each experimental session by means of an electronic balance. Solid-state logic circuitry for the control and recording of the experiment was located in a room adjacent to the experimental room.

$$
\text { PROCEDURE }
$$

The bird was run daily for 70 consecutive 3.5-h experimental sessions. The sequence of events is given in Table 1 along with the number of sessions for which each condition was in effect. During each reinforced session, 100 reinforcements were provided on whichever schedule was in progress. Reinforcement consisted of 2 -sec access to mixed grain. The key light and houselight were always on except during reinforcements when only the hopper light was on. The extinction (EXT) condition was exactly the same as the preceding VI 120 -sec condition except that no grain was put in to the grain hopper.

On the second day of the second FI 120-sec condition, the water beaker was moved to the side of the chamber, viz, by the door, opposite to where it had previously stood, because visual observation revealed that a superstitious pattern of behavior had developed which prevented the bird from ever coming into contact with the beaker.

In addition to the recorded daily water intake in the home cage, two control conditions for water intake in the experimental chamber were conducted. In the first, the nonfood condition, the bird was simply placed in the lighted chamber for $3.5 \mathrm{~h}$ each day. In the second, the continuous reinforcement (CRF) condition, the key light was turned on and the bird was permitted to obtain 100 reinforcements on CRF. The key light was then turned off and the bird stayed in the lighted chamber for the remainder of the 3.5 h. On Day 16, an FI 3C-sec schedule of
Table 1

Schedule (sec) and Control Conditions and their Duration (sessions) in Order of Presentation

\begin{tabular}{lc}
\hline Condition & Sessions \\
Nonfood & 8 \\
CRF & 7 \\
FI 30 & 1 \\
FI $120 \mathrm{~A}$ & 14 \\
FI $120 \mathrm{~b}$ & 9 \\
FI 180 & 4 \\
FI 60 & 3 \\
FI 30 & 1 \\
FI $120 \mathrm{~b}$ & 7 \\
VI $120 \mathrm{~A}$ & 6 \\
EXT & 3 \\
VI $120 \mathrm{~B}$ & 7 \\
\hline
\end{tabular}

reinforcement was used to insure sustained responding, and subsequently the series of schedule conditions was initiated.

RESULTS AND DISCUSSION

Figure 1 shows mean session water and food intake levels and their standard errors for selected experimental and control conditions. The data presented under FI 120B represent the combined results of the two FI 120 conditions, in which intake levels were highly similar. Water intake levels in the FI 120B, VI 120A, and VI 120B conditions represent increases of two to three times the levels observed in the nonfood and CRF control conditions and indicate that polydipsia had developed under the former conditions.

Other studies have used as a baseline for comparison either home cage water intake

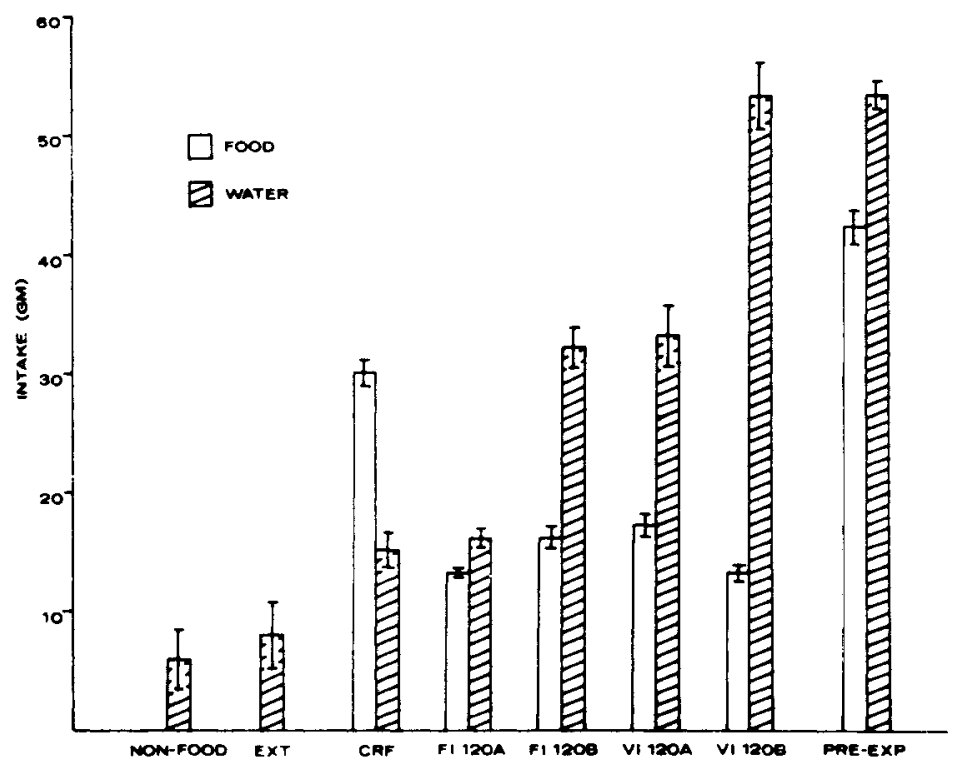

Fig. 1. Mean food and water intake (g) \pm SE during 3.5-h sessions for selected schedule and control conditions. 
at so i fre-feeding weight (Falk, 1964), or home eage water intake under free-feeding conditions ( $F$ alk, 1907). Home cage water intake at $80 \%$ free-feeding weight in this study was about $22 \mathrm{~g}$ per day, lending additional support to the conclusion that overdrinking was subsequently obtained. Moreover, several months before the start of this study, home cage free-feeding data for this bird had been collected following extended deprivation, which produced subsequent overeating (see Fig. 1, PRE-EXP). Although the level of water intake in this case appears abnormally high, it is consistent with the frequent observa. tion that water intake varies directly with level of food intake (Bolles, 1967). A final comparison may, therefore, be made between the mean overdrinking observed in this free-feeding condition and that in the VI 120B condition where the bird received only about $15 \mathrm{~g}$ of food per session. The fact that the same level of overdrinking is observed in the latter condition, which provided the bird with approximately one-third the amount of food obtained in the free-feeding condition, is further indication that polydipsia developed.

Mean session water intake for the FI 30 . FI 60, and FI 180-sec conditions (16, 19. and $25 \mathrm{~g}$. respectively) is not presented because it did not exceed control levels. This may have been due in part to an unforeseen confounding of reinforcement schedule and session food intake. It was found that although the number of reinforcements was held constant the amount of foud actually obtained was not constant across these sciledules.

Where session food intake remained constant, however, two manipulations were found to be associated with definite changes in level of drinking. The first concerns the position of the water source in the experimental chamber, which in this and other studies (Clark, 1962) seems to be a contributing factor to the development of polydipsia. The effect of a change in the position of the water source is reflected by the increase in session water intake from FI 120A to FI 120B (Fig. 1). To test for the possibility that this change in position had merely made the water more accessible to the bird, the water beaker was placed beside the feeder opening during one session of the second FI 120-sec condition. However, during this session, water intake dropped to $17 \mathrm{~g}$. Overdrinking, therefore, did not seem to be merely a function of the accessibility of the water, but was apparently related to a superstitious pattern of behavior which had previously developed (see Procedure). While the polydipsia observed under these conditions may not have been acquired by adventitious reinforcement with food, it may have been incorporated into a "continuous chain" (Segal el al, 1905) of behuvior leading from drinking to eating.

The second significant manipulation was the 3-day food-extinction condition, which resulted in an immediate reduction in session water intake to a very low level $(14 \mathrm{~g})$. Reinstating the same conditions of reinforcement (VI 120-sec) following extinction had the effect of producing a marked increase in session water intake over the preextinction level. This is shown in Fig. 1 by the difference between levels of drinking under the VI 120A and VI 120B conditions. Segal et al (1965) have reported that postextinction polydipsia returned to the preextinction level, but no mention of a sudden increase beyond this level was made. The postextinction increase in drinking found in this study is reminiscent of rate increases in behavioral contrast studies. However, whether or not the same variables can account for both polydipsia and contrast is an empirical question.

\section{REIERINCIS}

BOLLES, R. C. Theory of mutivation. New York: Harper and Row, 1967.

CLARK, F. C. Some observations on the adventitious reinforcement of drinking under food reinforcement. Journal of the Experimental Analysis of Behavior, 1962, 5, 61-63.

FALK, J. L. Studies on schedule-induced polydipsia. In M. J. Wayner (Ed.), Thirst: First intermational symposium on thirst in the regulation of body water. New York: Pergamon Press, 1964. Pp. 95-116.

FALK, J. L. Control of schedule-induced polydipsia: Type, size, and spacing of meals. Joumal of the Experimental Analysis of Behavior, 1967, 10, 199-206.

SEGAL, E. F., \& ODEN, D. L. Determinants of polydipsia in rats: A reply to Stein. 1 . Emptying the water bottle. Psychonomic Science, 1965, 2, 201-202.

STEIN, L. Exossive drinking in the rat Superstition or thirst? Journal of Comparative \& Physiological Psychology, 1964, 58, 237-242.

\section{NOTE}

1. This work was supported in part by L'SPHS Grant MH-05798 to D. Premack.

\section{Magnesium Pemoline: Effects on brightness discrimination using positive reward}

JOHN G. BRIDGE and GLEVV I. HATTOA, Michigan State Liniversity, tast Lansing. Mich. 7.8823

A drug grolup was stomach loaded with $20 \mathrm{mg} / \mathrm{kg}$. lagnesium Pemoline in tragacanth, and a control group was loaded with the vessel substance only. Performances in a $Y$ maze brightn'ss-discrimination task with sucrose reinforc'ment were compared: The drug group performed significantl! better in numing speed, latency, trials ani reinforcements to criterio'n, and percentage of correct choices. These results indicate that Magnesium Pemolinc' 'nhances learning br ad lib rats of a brightncss discrimination $Y$ maze with positive rcinforcement.

Plotnik off reported (1966) that Magnesium Pemoline (MgPem) enhances learning and retention of an avoidance response by rats; Glasky \& Simon (1966) suggested this was caused by stimulating synthesis of RNA.
These experiments generated a number of subsequent investigations of the effect of MgPem on learning, memory, and performance. Attempts to replicate the work of Glasky \& Simon failed (Stein \& Yellin, 1967). Powell, Martin, \& Kamano (1967) attempted to differentiate between "learning" and "performance"; their results indicated that the drug influences performance through its stimulant properties, but does not affect learning significantly. Plotnik off (1967) offered more evidence that MgPem enhances memory, but again results to the contrary were reported by others (Beach \& Kimble, 1967). Although there is considerable agreement on the stimulant properties of $\mathrm{MgPem}$, its effects on performance, learning, and memory are still highly controversial.

Most of the previous work with MgPem has been done with avoidance tasks; however, the present study was designed to measure performance with motivation 